Article

\title{
Numerical Analysis of the Transient Behaviour of a Variable Speed Pump-Turbine during a Pumping Power Reduction Scenario
}

\author{
Giorgio Pavesi *, Giovanna Cavazzini and Guido Ardizzon \\ Department of Industrial Engineering, University of Padova, 35131 Padova, Italy; \\ giovanna.cavazzini@unipd.it (G.C.); guido.ardizzon@unipd.it (G.A.) \\ * Correspondence: giorgio.pavesi@unipd.it; Tel.: +39-049-827-6768
}

Academic Editor: Juan Ignacio Pérez-Díaz

Received: 10 March 2016; Accepted: 27 June 2016; Published: 12 July 2016

\begin{abstract}
To achieve the carbon free electricity generation target for 2050, the penetration of renewable energy sources should further increase. To address the impacts of their unpredictable and intermittent characteristics on the future electricity grid, Pumped Hydro Energy Storage (PHES) plants should enhance their regulation capability by extending their continuous operating range far beyond the optimal normal working range. However, for the time being, the regulation capability of the new generation of PHES, equipped with reversible pump-turbines due to their cost-effectiveness, is limited at part load by instability problems. The aim of this paper is to analyse, during a pumping power reduction scenario, the onset and development of unsteady phenomena leading to unstable behaviour. A 3D transient numerical simulation was carried out on the first stage of a variable-speed two-stage pump-turbine from full load to the unstable operating zone by progressively reducing the speed from $100 \%$ to $88 \%$ rpm corresponding to a power reduction from full load to about $60 \%$ with a ramp rate of $1.5 \%$ per s. Two three-dimensional unsteady flow structures affecting the return channel and the wicket gates at the end of the first stage were identified and their evolution in the power regulation scenario was fluid-dynamically and spectrally characterized to determine the fluid-dynamical conditions causing the head drop in the hump zone.
\end{abstract}

Keywords: pump-turbine; adjustable speed hydro plants; dynamic response of hydro plants; hydro plant control

\section{Introduction}

Even though renewable energy sources have largely increased in the last years, their penetration in the world electricity generation should become much more significant in order to contribute to the reduction of greenhouse gas emissions (GHG).

The European Union policy has made great efforts towards developing these resources in response to environmental concerns, but their unpredictable and intermittent characteristics have restrained their deployment because of the negative impact on power system security, stability, reliability and efficiency [1]. The electricity grid is still a highly centralized interconnected network consisting of energy generating systems, transmission lines and demand centres with a limited use of energy storage. A significant energy storage capacity will be necessary to favour the deployment of an increasing share of renewable sources and to balance demand and supply continuously, by ensuring grid stability $[1,2]$.

Pumped Hydro Energy Storage plants (PHES) certainly represent one of the most cost-effective large-scale storage technologies $[3,4]$ with a cycle efficiency range of $75 \%-85 \%$ and competitive costs (800-1500€/kW 2016€) [5]. To face the more demanding performance of future electricity grids, PHES should increase their regulation capability by extending their continuous operating range far beyond 
the optimal normal working range. Two different configurations of pumped-hydro storage power plants can be identified: a binary set equipped with a reversible pump-turbine and a ternary set equipped with a turbine and a pump. The binary set is widely adopted due to its compactness and cost-effectiveness, but it is slower and less flexible than a ternary set due to the unstable behaviour affecting reversible pump-turbine machines at part-load both in pumping and in generating mode.

In pumping mode, the unstable behaviour may lead to anomalous loading due to the misalignment during shear pins assembly on the activation mechanism of the guide vane and to self-excited vibrations of the hydraulic system with risk of sever structural damage to the PHES. Therefore, to guarantee start-up and safe operation of the plant even under the highest head levels, proper margins to the unstable behaviour have to be assumed, further reducing the operating range and the regulation capacity on one side and forcing to increase the sizing of the machine on the other.

To partially overcome this limitation in operating range and hence in regulation capability, the new generation of PHES has adopted the variable speed technology, whose basic idea is to modify the rotation velocity of the machine in order to operate over a larger head range and pumping power input range than a single-speed unit [6,7]. By adjusting the speed, the unit does not have to wait until a block of power equal to its full pump capacity rating is available before starting to pump, but it can purchase blocks of pumping power over a load range of $60 \%-80 \%$ of rated pumping power, enabling more real-time response to grid conditions [2,8].

Even though this solution has allowed to increase the regulation capability of the plant, it is still not sufficient to face the increasingly wider stable operating range required by the increasing share of renewable energy sources, and, hence, stability limits positioned considerable far from the normal operating range will be mandatory [9].

The unstable behaviour has been related to a strong fluid-dynamical interaction between rotor and stator parts that causes the development of unsteady phenomena, such as a rotating stall. These phenomena determine a significant increase of the hydraulic losses in the rotor and/or in the stator part with a consequent head drop in the pump-turbine performance, associated in the head-discharge curve with a change in slope from negative to positive $(\mathrm{dH} / \mathrm{dQ}>0)$, the so-called "hump" zone.

The first studies on the relationship between rotor-stator interaction and mechanical vibrations mainly focused on the interaction of the wake from a runner blade with the diffuser blade and argued the influence of the instantaneous position of the runner blade trailing edge relative to the diffuser vane leading edge [10,11].

Sinha et al. [12] and Sano et al. [13] focused for the first time on the hump zone, highlighting the influence of the radial gap between runner and diffuser on the characteristics of the flow instabilities developing inside the diffuser. In particular, Sano et al. [13] demonstrated that the radial gap affects the onset or not of a "leakage flow", passing from one diffuser passage to the adjacent one through the radial gap, which causes the evolution from a stationary stall to a rotating stall.

Gonzales et al. [14] was one of the first studies, presenting both experimental and numerical analyses on the rotor-stator interaction. They demonstrated the capability of the numerical analysis to simulate the effects of the runner blade passage in front of the volute tongue correctly, highlighting the importance of not assuming a fixed mass flow rate at the inlet of the computational domain, physically unsuitable for unsteady simulations.

More accurate numerical results on a six-bladed centrifugal pump were obtained by Byskov et al. [15], applying for the first time the Large Eddy Simulation (LES) model. Their analysis identified at part load in the runner the development of a steady non-rotating "two-channel" stall phenomenon characterized by alternate stalled and unstalled passages. Their results compared with PIV results obtained in a previous experimental analysis [16] had better predicted the flow field evolution than the most common turbulence models of those years ( $k-\varepsilon$ and Baldwin-Lomax turbulence models). 
Another numerical analysis was presented by Sano et al. [17], demonstrating the development of a rotating stall which causes in the diffuser channels the switching between reverse and jet flows, in good agreement with experimental results.

Unsteady reverse and jet flows in the guide vanes, interacting with blocking vortexes located in the return channel, were also numerically identified by Cavazzini et al. [18].

The circumferential distortion of the pressure distribution at the runner outlet due to the rotor-stator interaction was also confirmed by Majidi [19], who demonstrated the influence of the pressure fluctuations on the runner blade loading and on the mass flow rate through the runner blade passages with the possible onset of dangerous dynamic effects [20].

The frequency content of the pressure pulsations was analysed by Pavesi et al. [21], adopting for the first time in this research field the wavelet analysis to characterize the onset and development of the unsteady phenomena both in the frequency and time-frequency analysis.

A first relation with the pump-turbine geometry was highlighted by Gentner et al. [22], who demonstrated the dependence of the characteristics of the flow instabilities on the specific speed. For high values of the specific speed, the unstable behaviour in the hump zone was related to the onset of a recirculation zone at the runner inlet near the shroud and the blade leading edge. For low specific speed, the recirculation zone is still identified but the head drop occurs only when this zone interacts with a stall developing in the diffuser.

Yang et al. [23] experimentally studied the flow field in a low specific speed pump-turbine by high-speed camera and miniaturized pressure transducers, identifying the development in the stator parts of two phenomena. The first one, developing in the return channel even in the stable branch of the head-discharge curve, interacts with a second one, developing in the guide vane channels and this interaction causes the head drop in the head-discharge curve.

Even though the flow field characteristics at fixed operating conditions in and outside the hump zone of a pump-turbine have been widely investigated, to the authors' knowledge, no one has ever experimentally or numerically considered a real regulation scenario in order to determine the time-varying fluid-dynamic conditions causing the head drop in the hump zone.

The paper presents an in-depth study of the onset and development of the unsteady phenomena leading to the unstable behaviour of a pump-turbine during a pumping power reduction scenario from full load to the hump zone. A 3D transient flow simulation was carried out on the entire model of a pump-turbine by means of a commercial CFD program, adopting an adjustable-speed approach with a power ramp rate of $1.5 \%$ per $\mathrm{s}$.

\section{Numerical Model}

Numerical analyses were carried out by the commercial software ANSYS 15.0 on the first stage of a two stage reversible pump-turbine in pump-operating mode (Figure 1). Table 1 reports the main geometrical data of the scaled down pump-turbine model. In the analysed configuration, the relative azimuthal position of the guide vanes was fixed by rotating the whole guide vane system from the face-to-face configuration $\left(\lambda=0^{\circ}\right)$ of $+8^{\circ}$ out of alignment. The radial gap between the trailing edge of the guide vanes and the runner tip was $10.5 \mathrm{~mm}$, which is $5.25 \%$ of the impeller radius.

The computational domain was divided into four components for grid generation. Structural meshes were used to discretize inlet duct, impeller, wicket vanes, return channel and leakage system. Figure 2 reports the meridional scheme of the model. 


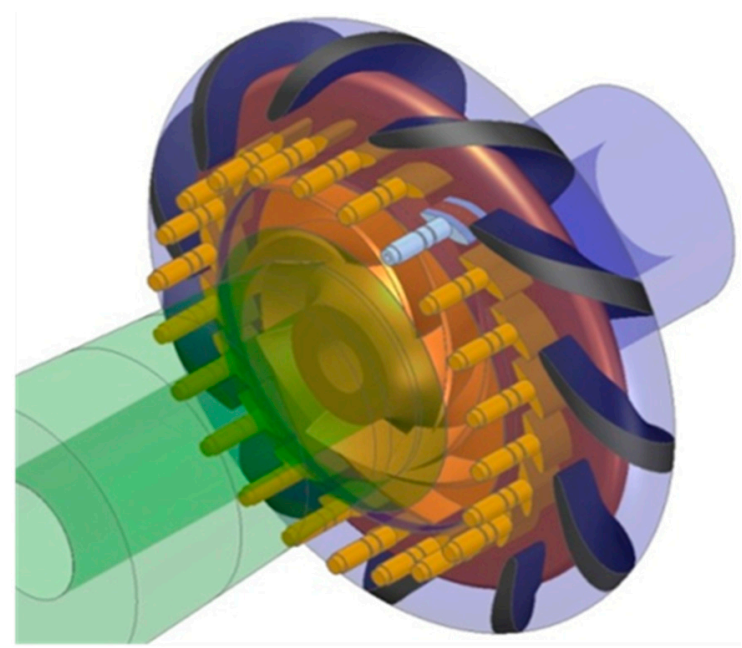

Figure 1. 3D scheme of the tested configuration.

Table 1. Geometry characteristics and performance parameters of the tested pump-turbine.

\begin{tabular}{ccccc}
\hline \multicolumn{5}{c}{ Impeller Data } \\
\hline $\mathrm{D}_{2}(\mathrm{~mm})$ & $\mathrm{B}_{2}(\mathrm{~mm})$ & $\mathrm{n}_{\mathrm{b}}$ & $\beta_{2 \mathrm{~b}}\left(^{\circ}\right)$ & $\varphi_{\text {Des }}$ \\
400 & 40 & 7 & 26.5 & 0.125 \\
\hline \multicolumn{5}{c}{ Wicket Guide Data } \\
\hline $\mathrm{D}_{3}(\mathrm{~mm})$ & $\mathrm{B}_{3}(\mathrm{~mm})$ & $\mathrm{n}_{\mathrm{bW}}$ & $\alpha_{3 \mathrm{~b}}\left(^{\circ}\right)$ & $\lambda\left(^{\circ}\right)$ \\
410 & 40 & 22 & $10 \div 30$ & $-8 \div 8$ \\
\hline \multicolumn{5}{c}{ Return Channel Vanes Data } \\
\hline $\mathrm{D}_{4}(\mathrm{~mm})$ & $\mathrm{B}_{4}(\mathrm{~mm})$ & $\mathrm{n}_{\mathrm{bR}}$ & $\alpha_{4 \mathrm{~b}}\left(^{\circ}\right)$ \\
516 & 40 & 11 & 30 \\
\hline
\end{tabular}

4: inlet return channel; b: blade.

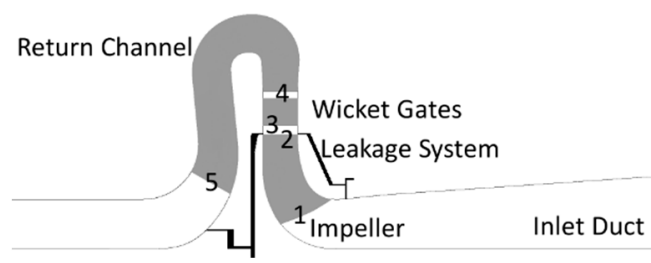

Figure 2. Meridional view of the numerical model. Regions filled in grey refer to the blades; region filled in black refers to the leakage system. 2: outlet impeller; 3: inlet wicket gate; 4: inlet return channel.

The inlet duct was discretized by a mesh of about 339,500 elements with a y+ values lower than 20. As regards the impeller, an $\mathrm{H}$ mesh with an $\mathrm{O}$ grid was performed. The stage head $\mathrm{H}$ and the stage efficiency were evaluated in preliminary tests to assure grid independent solution for the runner and to guarantee the capacity of numerical solution to capture the local pressure pulsations as well. Even if the sensitivity analysis highlighted a grid independent solution with about 200,000 elements per passage, the intensity and the extent of the local pressure pulsations appeared to be correctly evaluated only with grid greater than 300,000 elements per passage. To be sure of the capacity of the numerical solution to capture local pressure pulsations in the whole domain, as a precautionary measure, the adopted number of elements was further increased to 565,000. The resulting runner computational domain that was used had 3.96 million of cells with y+ values below 15 .

O-type grids were adopted for both the wicket gate and the return channel discretization. Following the same philosophy used for the impeller the number of elements was increased to 
about 4.3 and 5.4 million of cells, respectively. The leakage from the labyrinth seal was also considered and several H-blocks were built to describe the cavities. Figure 3 reports details of the meshed domains.

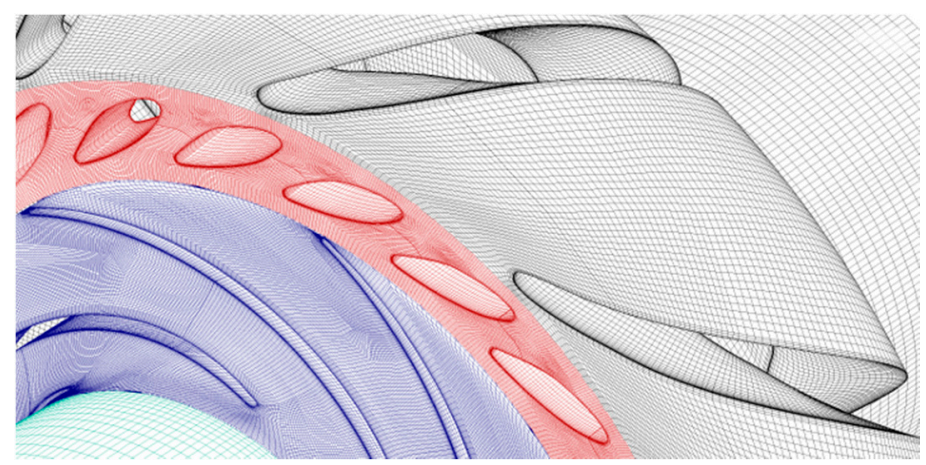

Figure 3. Detail of the coarse mesh of the numerical model: inlet duct, impeller, wicket gates and return channel.

The choice of the turbulence model is a key issue in CFD. According to the large flow separations expected at part load, a Detached Eddy Simulation (DES) model was adopted. On both blades and end walls, the boundary layer was assumed fully turbulent. All the interfaces between stator-rotor blocks were standard transient sliding interfaces.

At the inlet boundary condition, the total pressure was imposed with the values taken from the experimental data. At the outlet, due to the highly disturbed flow field, an opening condition with average static pressures was fixed.

The power reduction was simulated by a time-varying boundary condition. The impeller was slowed down from $100 \%$ to $88 \%$ rpm corresponding from full load to about $56 \%$ of the full load power with a ramp rate of $1.5 \%$ per s, and both the total pressure and the static pressure were varied according to the experimental values obtained under steady conditions.

The influence of time step and of the number of iterations per time step on the flow convergence was evaluated comparing the evolution of the flow field in a dynamic power reduction scenario of $0.3 \mathrm{~s}$ starting from the part load of $63 \%$ of $\mathrm{Q}_{\mathrm{BEP}}$ and $100 \% \mathrm{rpm}$.

Two time steps were considered, corresponding to a rotation of $1^{\circ}$ and $0.5^{\circ}$, whereas three number of iterations (5, 7 and 9) per each time step were analysed. The power spectra of all the monitor variables considered in this paper did not highlight noteworthy differences. Consistently, a second order implicit time stepping was adopted with a time step corresponding to a rotation of $1^{\circ}$ and $5^{\circ}$ iteration per time step. The root mean square Courant number was found to be lower than 1.9 for all power reduction, guaranteeing an accurate resolution of the transient details. The maximum resulting RMS values for the residuals were u momentum $10^{-4}$, v momentum $10^{-4}$, w momentum $3 \times 10^{-5}$, and turbulence kinetic energy $10^{-4}$.

\section{Results}

\subsection{Validation of Numerical Model under Constant Flow Rate Conditions}

In order to validate the accuracy of the numerical simulations, the experimental data obtained according to ISO standards from Dep. Industrial Engineering-University of Padova was compared with the steady simulations.

The global measurements have been performed following IEC recommendations with a $0.1 \%$ precision for head in the vicinity of the best efficiency point and $0.3 \%$ for the overall domain. The accuracy in the calculation of the speed of the machines was $\pm 0.5 \mathrm{rpm}$. The calibration of the instruments was performed on site. 
Numerical analyses were carried out for some operating points at a constant rotation speed of $600 \mathrm{rpm}$. The numerical data were acquired for five impeller revolutions after more than 20 revolutions required to achieve a quasi-steady simulation convergence. The comparison in terms of head is reported in Figure 4.

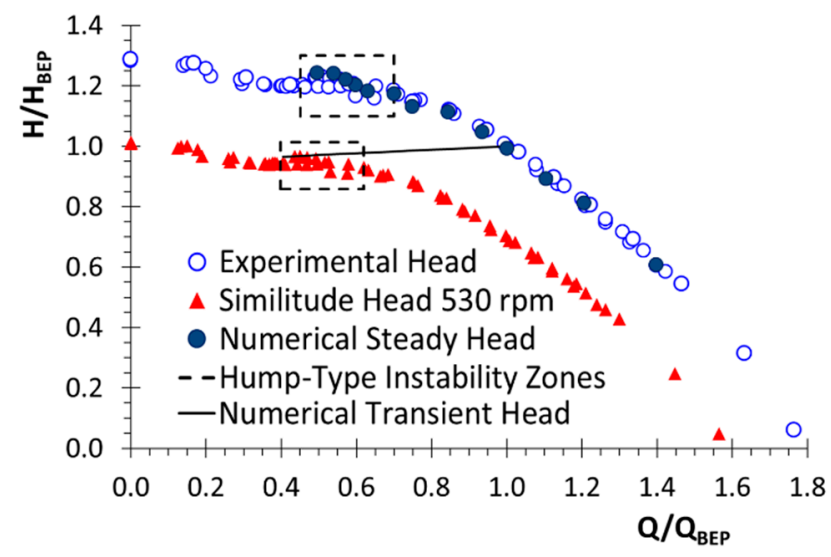

Figure 4. Comparison between numerical and experimental head curves.

The maximum percentage error of $-3.84 \%$ in head between the experiment and simulation was observed just before the hump-type instability zone. The head showed a tendency to smaller prediction than the experimental data at the BEP $(-1.49 \%)$ and a tendency to a greater prediction in the hump type instability zone $(\max +1.24 \%)$. The errors may be arising from the practical limitations in the numerical model but all the errors between the simulation and experiment are in a reasonable range not only at BEP conditions.

\subsection{Numerical Analysis of the Pump-Turbine in a Power Reduction Scenario}

To study the evolution of the flow field in a dynamic power reduction scenario, the wicket vane was fixed at $18^{\circ}$ and kept constant during the simulation.

The transient numerical simulation on the entire machine was carried out with a time-varying boundary condition in which the impeller speed was reduced every time step whereas the total pressure at inlet and the average static pressure at outlet were varied according to the experimental values obtained at steady conditions.

The initialization was based on the results of the steady simulation carried out for the BEP flow rate and a simple linear variation of the impeller speed from $100 \%$ to $88 \%$ was fixed.

In Figure 4, the characteristic obtained by the similarity laws at $530 \mathrm{rpm}$ is shown. At the lowest impeller speed, the head in the dynamic simulations intersects the hump zone.

At higher speed factors $\left(-0.482<\mathrm{n}_{\mathrm{ED}}<-0.472\right)$, the wicket gate channels experience flow rate oscillation (Figure 5) and 11 channels with low flow rate are alternated by 11 channels with higher flow rate. This trend is due to the interaction with the return channel blades and it is consistent with the blockage effect due to the out of alignment of wicket gates with the return blades (Figure 3).

As the organised flow oscillation continually loses coherence, it breaks up progressively, and the flow rate distribution remains quite constant with an alternation of return channel with low and high flow rates (Figure 6) $\left(-0.470<\mathrm{n}_{\mathrm{ED}}<-0.450\right)$.

Close to the hump zone $\left(-0.447<\mathrm{n}_{\mathrm{ED}}<-0.435\right)$, the flow field evolves in a rotating partial stall moving from one group of adjacent wicket gate channels to the subsequent one according to the runner rotation direction as highlighted in Figure 5. 


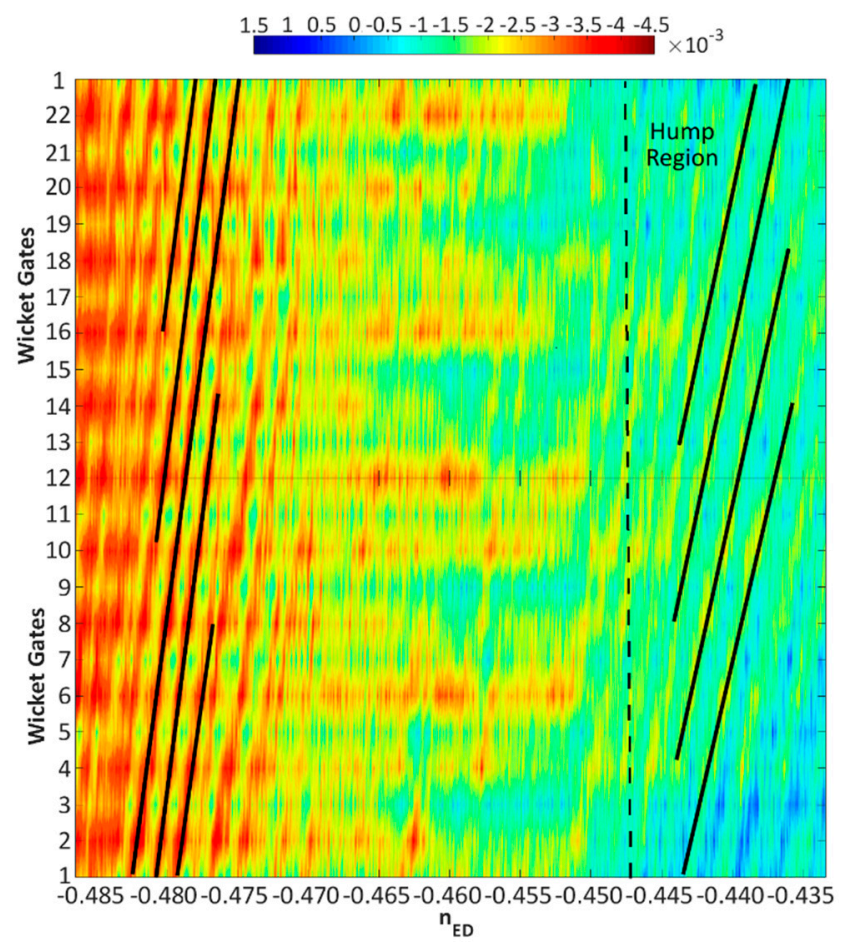

Figure 5. Numerical dimensionless discharge factor $\mathrm{Q}_{\mathrm{ED}}$ in the wicket gates.

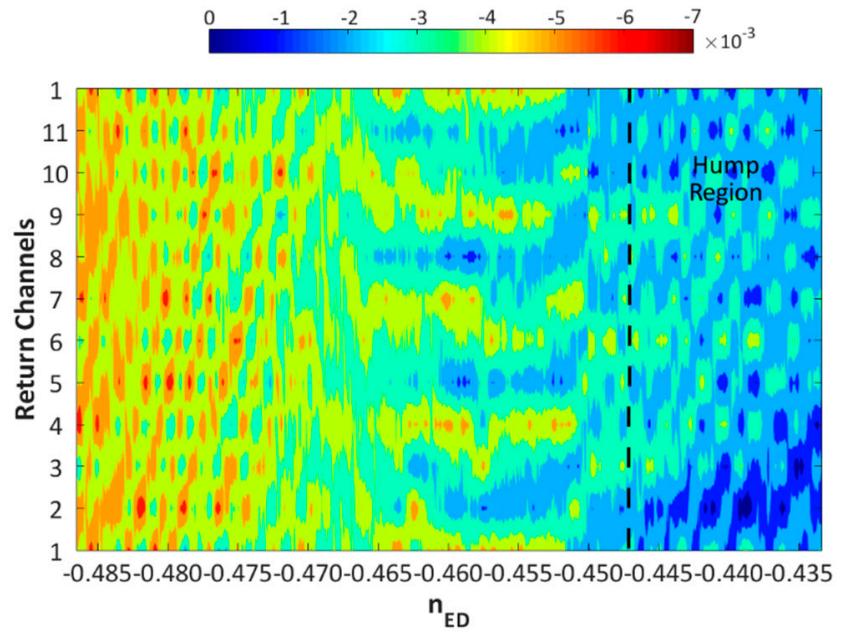

Figure 6. Numerical dimensionless discharge factor $\mathrm{Q}_{\mathrm{ED}}$ in the return channels.

In the return channel, the flow field is perturbed and shows the same sequences highlighted in the wicket gates, a flow rate oscillation, a quasi-steady flow distribution and, in the hump zone, the rotating stall (Figure 6).

The return channels are characterized by vortexes partially blocking the channels (Figure 7) and forcing the streamlines to climb over the reverse flow volume presents in the corner between the vane suction side and the U-Turn hub.

At the beginning of the transient process, a small vortex core region can be observed, located close to stay vanes outlet. These vortex core regions are generated by wakes of wicket gates, flow separation vortices on the suction surfaces and mainly by wicket and return blades' interaction. 


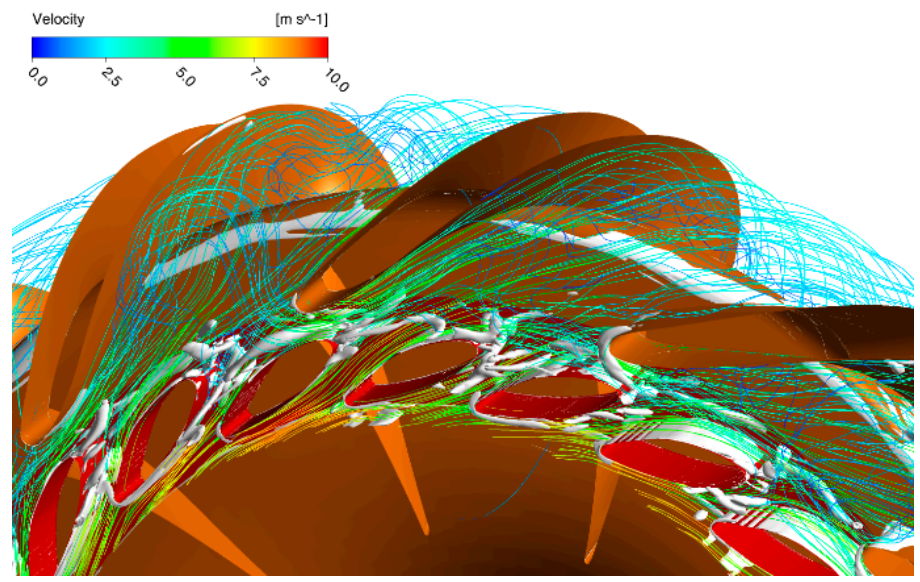

Figure 7. Distribution of streamline and vortex core $\left(\mathrm{Q}-\right.$ Criterion $\left.=90,000 \mathrm{~s}^{-2}\right)$ in stay vanes, for $\mathrm{n}_{\mathrm{ED}}=-0.480$.

Due to this interaction, a wave rings is generated that forces the flow rate to migrate to one return channel after the other, inducing the flow rate oscillation highlighted in Figures 5 and 6.

At $\mathrm{n}_{\mathrm{ED}}<-0.465$ (Figures 8 and 9), the vortex core regions show many more effects. The vortex core regions almost block the stay vanes' passages.

First, as shown in Figure 8, the velocity appears with fluctuation in the stay vanes but the flow rate splitting up remain stable in the transient process up to about $\mathrm{n}_{\mathrm{ED}}=-0.45$. The back flow volumes in the return vane channels become quite stable and the flow rate tend to remain quite constant in all the return channels (Figure 6) and the flow path does not change evidently.

With the decrease of impeller speed, the vortex core regions increase and velocity appear with serious fluctuations in the stay vanes (Figure 9). During the power reduction, the perturbation of the pump-turbine flow field evolves in a rotating partial stall of five cells moving from one channel to the subsequent one according to the runner rotation direction as highlighted in Figure 6.

The development of these unsteady phenomena in the stators affected the pressure distribution on the vanes, thereby modifying their load distribution and induces dynamic load on the shear pin or the guide vanes' stem.

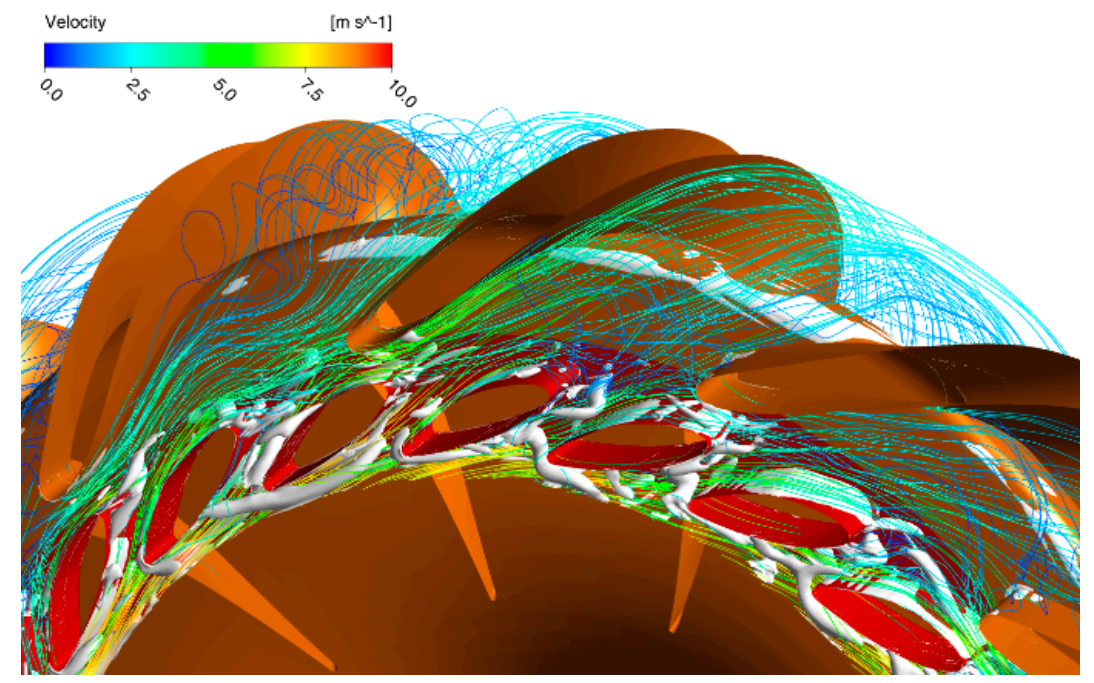

Figure 8. Distribution of streamline and vortex core (Q-Criterion $=90,000 \mathrm{~s}^{-2}$ ) in stay vanes, for $\mathrm{n}_{\mathrm{ED}}=-0.457$. 


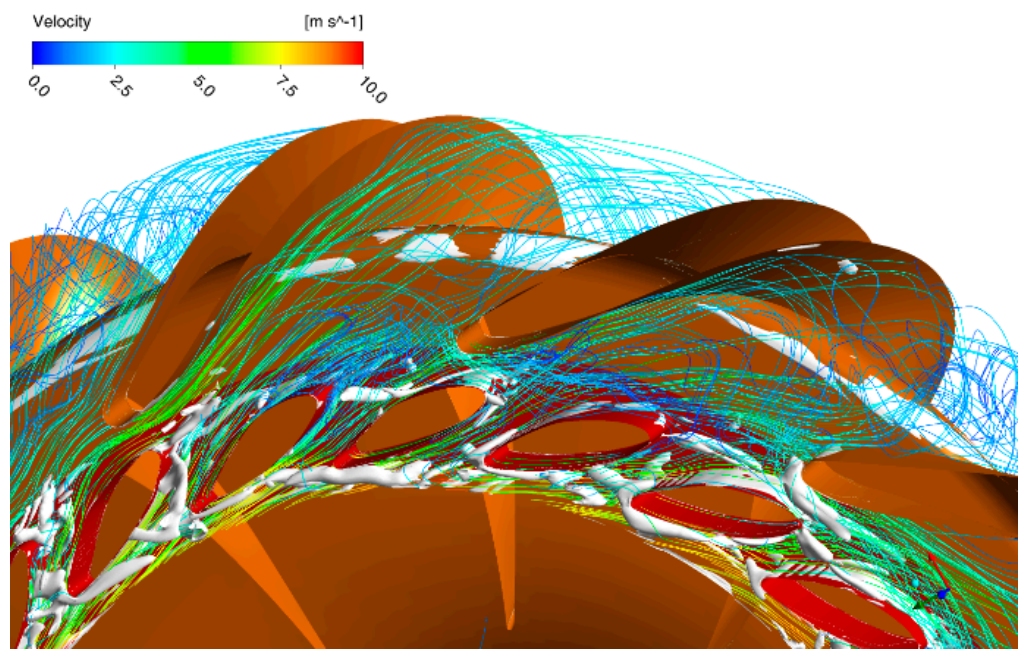

Figure 9. Distribution of streamline and vortex core (Q-Criterion $=90,000 \mathrm{~s}^{-2}$ ) in stay vanes, for $\mathrm{n}_{\mathrm{ED}}=-0.439$.

To obtain the variation of pressure in the transient process, monitoring points were created in the whole pump-turbine model (see Figure 10). Twelve points were defined in each wicket vane, 19 points in each return vane and 57 in each impeller blade.

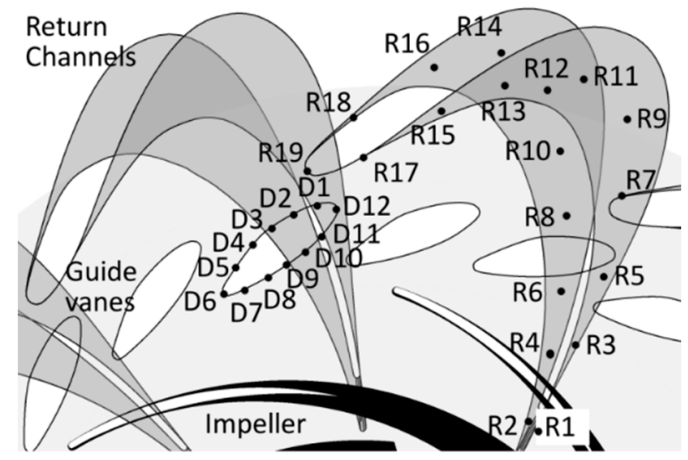

Figure 10. Detail and sketch of the tested configuration $\left(\lambda=8^{\circ}\right)$ with the distribution of monitor points.

Spectral analyses in frequency and in time-frequency domain were carried out to characterize the unsteady phenomena identified in the previous flow field analysis.

The frequency content of the numerical signals, acquired at each time step during the whole simulation of power reduction, was determined by using a Hamming window in the Lomb periodogram.

Figure 11 reports the power spectrum of the flow rate signal acquired in the wicket gates and return channels.

The spectrum is dominated by peaks at low frequency (St $<0.15)$, whose amplitude is greater than that of the blade passage frequency $(\mathrm{St}=1)$.

Figure 12 reports the continuous wavelet transform of the signals of the flow rate passing through a return channel.

The frequency, corresponding to the flow variation, is clearly identifiable, and starts to appear from nearly the BEP flow rate. The intensity of the flow variation reached a maximum after about a power reduction of the $11 \%$. With further reduction of the impeller rotational speed, the flow field perturbation into the pump turbine evolves and the organized rotating flow rate oscillation disappears replaced by a flow fluctuation dominated by a very low frequency $(\mathrm{St} \leqslant 0.002)$. 


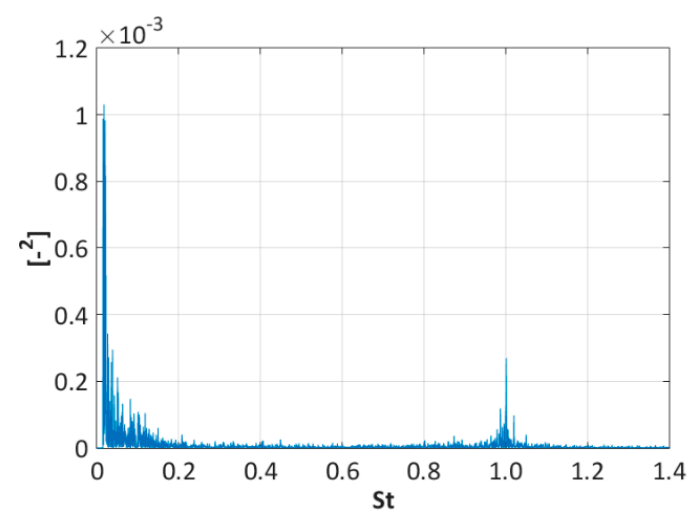

(a)

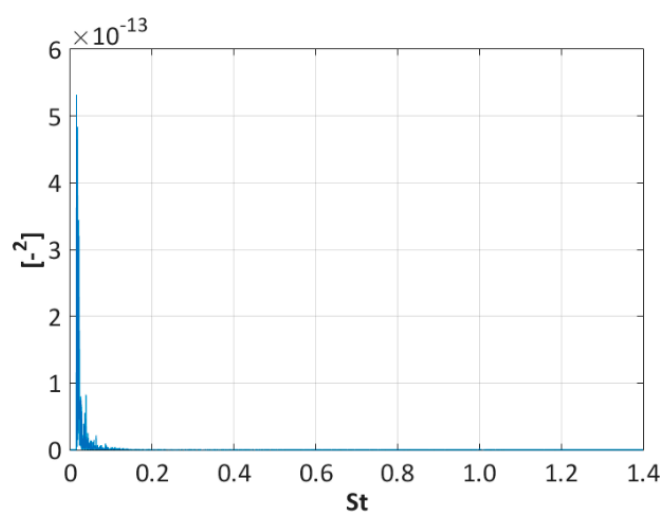

(b)

Figure 11. Power spectra density of the discharge factor $\mathrm{Q}_{\mathrm{ED}}$ acquired in the (a) wicket gate and (b) return channels.

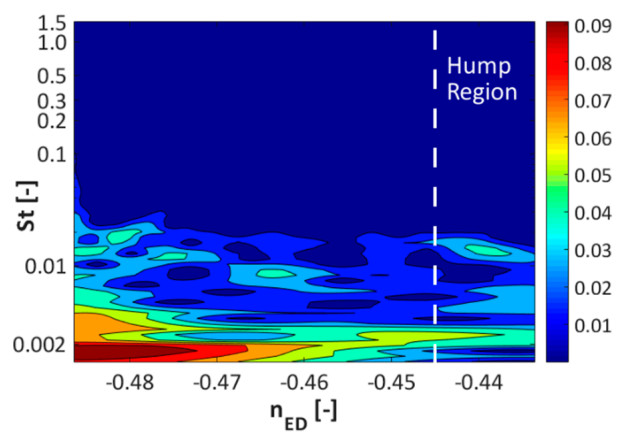

Figure 12. Normalized power-spectra of the discharge factor $\mathrm{Q}_{\mathrm{ED}}$ acquired in the return channels.

A further reduction of the impeller speed forces the pump to work into the hump zone (Figure 4). Flow field appears as an organized rotating partial stall (Figure 9) and the fluctuations are dominated by the frequency $\mathrm{St}=0.014$.

Consistently, the stator elements experience a phase of dynamic loads.

This remark is confirmed by the normalized power-spectra of the pressure, torque and force coefficients that are reported from Figures 13 to 17. At the wicket blade leading edges, due to the proximity of the runner outlet, the pressure pulsation, caused by the rotation of the impeller blades, is perceived by the guide vanes, but during the power reduction scenario the pressure pulsation peak is reached during the rotating stall phase (Figure 13). Moreover the wicket blade between two return vanes (Figure 13a) shows pressure variation not far from the BEP. In the gap between the wicket gate and the return blade, the flow field is accelerated and stabilized, whereas in the passage between the wicket blades between two return vanes, the vortex nuclei are not stable and when the flow rate oscillation appears, the time-frequency analyses highlight the start-up of pressure pulsations.

The spectral characterization at the wicket blade trailing edges (monitor point D12, Figure 14a) and return vane leading edge (monitor point R19, Figure 15a) demonstrates the strong interaction between the wicket blade and the return vane. The frequency, corresponding to the flow variation into the channels, is clearly identifiable, and starts to appear from nearly the BEP flow rate. The intensity of the pressure variation reached a first maximum after a power reduction of about $11 \%$ when the flow oscillation in the return vanes is higher (Figure 6). With a further reduction of the impeller rotational speed, the flow field perturbation into the pump turbine evolves and the flow oscillation disappears replaced by a quasi-steady flow distribution. Going into the return channels with low flow rate, the flow path is unstable and it generates pressure fluctuation in a spread range at sub-tonal frequency 
(Figure 15a). The flow field into the wickets gates channel starts to manifest a full three-dimensional flow structure.
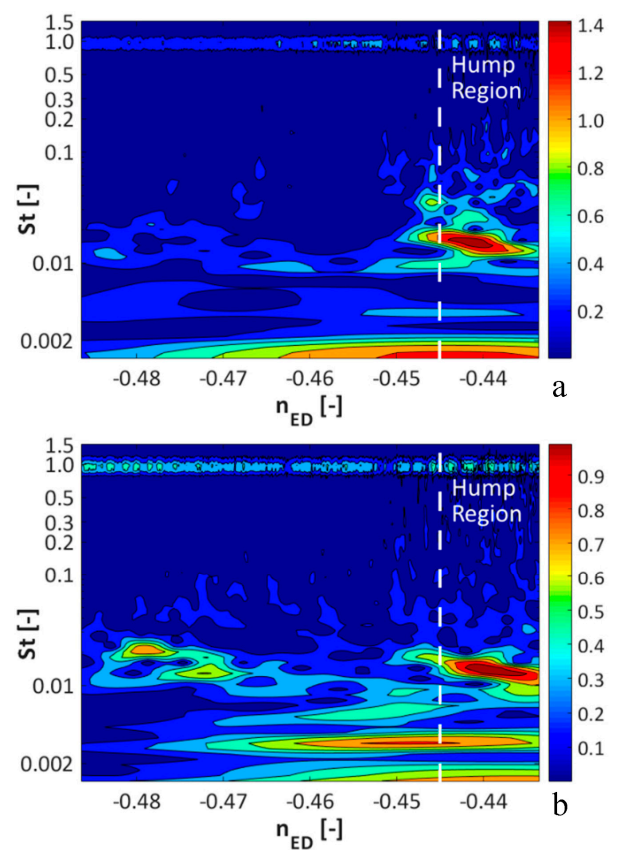

Figure 13. Normalized power-spectra of pressure coefficient $c_{p}$ evaluated in the monitor point D06 (Figure 10) of two consecutive wicket gates: (a) Wicket blade faced to the return vane; (b) Wicket blade between two return vanes.
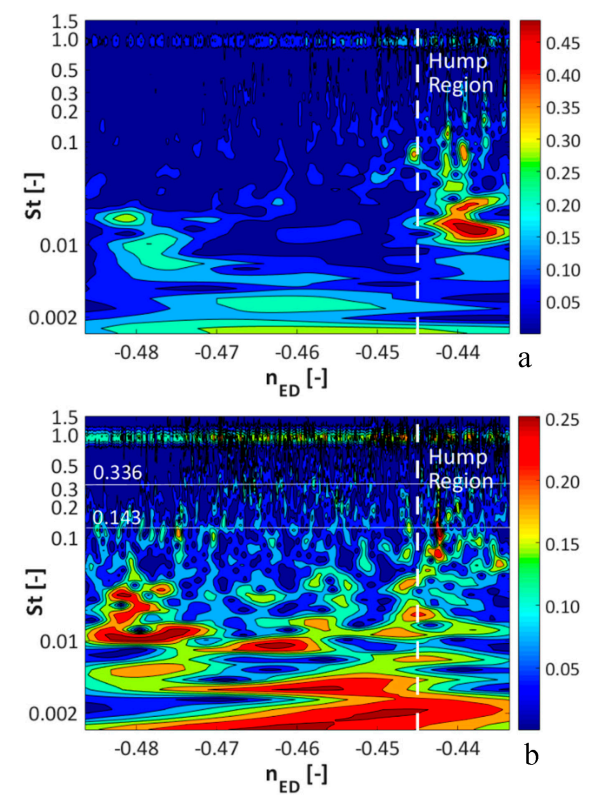

Figure 14. Normalized power-spectra of pressure coefficient $c_{p}$ evaluated in the monitor point D12 (Figure 10) of two consecutive wicket gates: (a) Wicket blade faced to the return vane; (b) Wicket blade between two return vanes. 

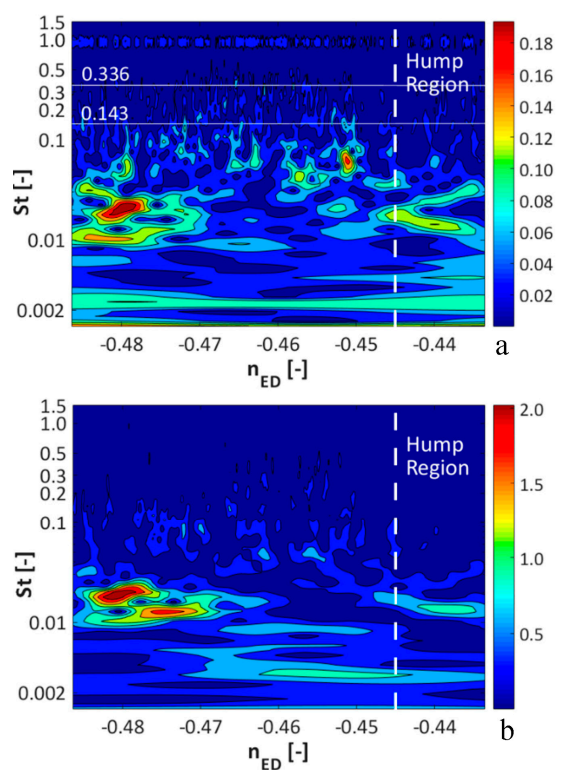

Figure 15. Normalized power-spectra of pressure coefficient $c_{p}$ evaluated in the monitor point (a) R11 and (b) R19 (Figure 10) of a return channel.

These disturbances, related to the boundary layer separation and stall, were noticed with images of the amplitude at a frequency very close to the impeller frequency $\mathrm{St}=0.143$ and to the sub-tonal frequency St $\approx 0.335$ identified by experimental measurements [24-26] also in steady conditions. With a further reduction of the impeller speed, the rotating partial stall rules the interactions. Consistently, torque and forces are dominated by very low frequencies (Figures 16 and 17).
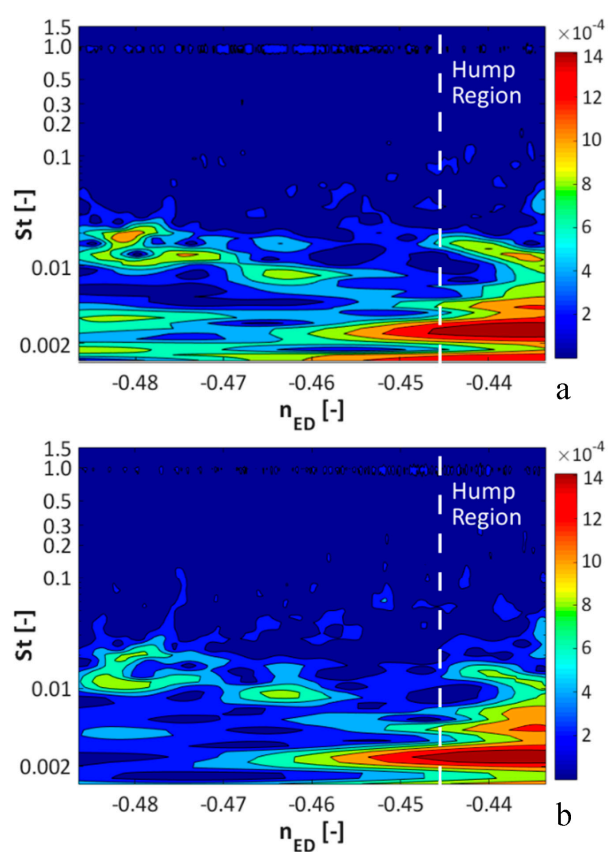

Figure 16. Normalized power-spectra of torque coefficient $\mathrm{T}_{\mathrm{ED}}$ of two consecutive wicket gates: (a) Wicket blade faced to the return vane; (b) Wicket blade between two return vanes. 

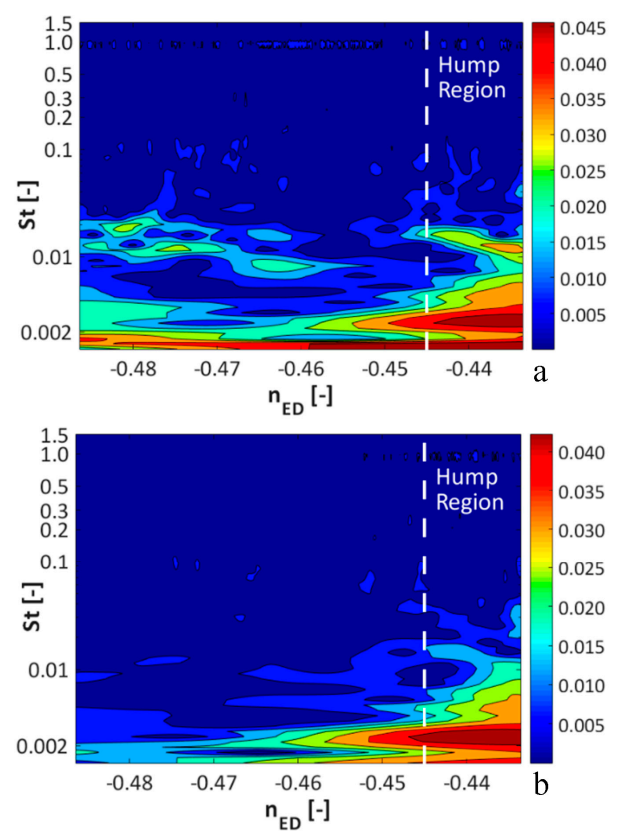

Figure 17. Normalized power-spectra of force coefficient on the pin of two consecutive wicket gates: (a) Wicket blade faced to the return vane; (b) Wicket blade between two return vanes.

\section{Conclusions}

3D incompressible transient simulation of a variable speed pump-turbine during a pumping power reduction scenario was performed using DES turbulence model. Numerical accuracy was validated using the steady experimental data.

The pressure and the torque variation in time and frequency domains were used to analyse the flow field when the impeller was slow down from $100 \%$ to $88 \%$ rpm corresponding to a power reduction from full load to about $46 \%$ with a ramp rate of $1.5 \%$. The major achievements obtained in this research are summarized in the following:

1. During the beginning of the power reduction process, the vortex, partially blocking the regular flow, moves from one channel to the subsequent one in the runner rotation direction with increasing intensity during the load rejection. Each steady channel alternates partial blocked flow according to the rotation frequency of the stall cell. The unsteady pattern in return channel strengthened, emphasizing its characteristic frequency with the rotational velocity decreasing, reaching a maximum and then disappearing. During this phase, the variation of force and torque on wicket gate pins is moderate.

2. For lower rotational speed, the periodic flow oscillation inside the return channels disappeared. The flow field into the wicket gates channel start to manifest a full three-dimensional flow structure. The path analyses show that only the vortexes with intensity and structure changed stochastically. Hence, the fluctuations of pressure and torque for different monitoring points show relatively low variation.

3. Close to the end of the power reduction process, serious fluctuations of both pressure and velocity could be observed, and the highest level occurs in the stay vanes showing a rotating stall. The parameters show serious fluctuations of torque and force on the guide vanes.

Acknowledgments: The project was supported by the University of Padova (No. CPDA130025/13).

Author Contributions: Giorgio Pavesi conceived, designed the test case, analyzed the results and wrote the paper; Giovanna Cavazzini and Guido Ardizzon contributed in results analyses and in the paper draft.

Conflicts of Interest: The authors declare no conflict of interest. 


\section{Nomenclature}

$\begin{array}{lll}\mathrm{B} & \text { Impeller or guide vane or return channel width } & \mathrm{m} \\ c_{p}=\frac{\mathrm{p}-\bar{p}}{\rho\left(\omega \frac{\mathrm{D}_{2}}{2}\right)^{2}} & \text { Pressure coefficient } & - \\ \mathrm{D} & \text { Diameter } & \mathrm{m} \\ \mathrm{F} & \text { Force } & \mathrm{N} \\ \mathrm{F}_{\mathrm{ED}}=\frac{\mathrm{F}}{\rho \mathrm{D}_{2}^{2} \mathrm{gH}} & \text { Force Factor } & - \\ \mathrm{g} & \text { Gravitational acceleration } & \mathrm{m} \cdot \mathrm{s}^{-2} \\ \mathrm{Gxx} & \text { Power spectra } & {[]^{2}} \\ \mathrm{H} & \text { Head } & \mathrm{m} \\ \mathrm{n} & \text { Rotational speed of the impeller } & \mathrm{rpm} \\ \mathrm{n}_{\mathrm{ED}}=\frac{\mathrm{nD}}{60 \sqrt{\mathrm{gH}}} & \text { Speed factor } & - \\ \mathrm{n}_{\mathrm{b}} & \text { Impeller number of blades } & - \\ \mathrm{n}_{\mathrm{bR}} & \text { Return Vane number of blades } & - \\ \mathrm{n}_{\mathrm{bW}} & \text { Wicket Guide number of blades } & - \\ \mathrm{Q} & \text { Flow rate } & - \\ \mathrm{p} & \text { Pressure } & \mathrm{m} \cdot \mathrm{s}^{-1} \\ \overline{\mathrm{p}} & \text { Pressure averaged along the time } & \mathrm{Pa} \\ \mathrm{Q} & \text { Discharge factor } & \mathrm{Pa} \\ \mathrm{BPF}=\frac{\mathrm{Q}}{\mathrm{D}_{\mathrm{b} n}^{2} \sqrt{\mathrm{gH}}} & \text { Blade Passage Frequency } & - \\ \mathrm{St}=\frac{\mathrm{f}}{\mathrm{BPF}} & \text { Strouhal number } & \mathrm{T} \\ \mathrm{T}_{\mathrm{ED}}=\frac{\mathrm{T}}{\rho \mathrm{D}_{2}^{3} \mathrm{gH}} & \text { Torque factor } & \mathrm{Hz} \\ \alpha & \text { Angle } & - \\ \beta & \text { Angle } & - \\ \lambda & \text { Guide vanes' azimuthally position } & \text { degree } \\ \omega & \text { Angular rotational velocity } & \text { degree } \\ & & \mathrm{degree} \\ & \mathrm{rad} \cdot \mathrm{s}^{-1}\end{array}$

\section{Abbreviations}

The following abbreviations are used in this manuscript:

$\begin{array}{ll}\text { PHES } & \text { Pumped Hydro Energy Storage } \\ \text { CFD } & \text { Computational Fluid Dynamics } \\ \text { BEP } & \text { Best Efficiency Point } \\ \text { BPF } & \text { Blade Passage Frequency }\end{array}$

\section{References}

1. European Transmission System Operators (ENTSO); European Wind Integration Study (EWIS). Towards a Successful Integration of Large Scale Wind Power into European Electricity Grids; Final Report; European Transmission System Operators: Brussels, Belgium, 2010.

2. European Commission (EC). Technology Map of the European Strategic Energy Technology Plan (SET-Plan)—Part I: Technology Descriptions; EUR 26345 EN; European Commission: Petten, The Netherlands, 2013.

3. Anagnostopoulos, J.S.; Papantonis, D.E. Study of pumped storage schemes to support high RES penetration in the electric power system in Greece. Energy 2012, 45, 416-423. [CrossRef]

4. Steffen, B. Prospects for pumped-hydro storage in Germany. Energy Policy 2012, 45, 420-429. [CrossRef]

5. World Energy Council. E-storage: Shifting from Cost to Value-Wind and Solar Applications; World Energy Council: London, UK, 2016.

6. Ciocan, G.D.; Teller, O.; Czerwinski, F. Variable Speed Pump-Turbines Technology. UPB Sci. Bull. Ser. D 2012, 74, 33-42.

7. Sivakumar, N.; Das, D.; Padhy, N.P. Variable speed operation of reversible pump-turbines at Kadamparai pumped storage plant-A case study. Energy Convers. Manag. 2014, 78, 96-104. [CrossRef] 
8. Schlunegger, H.; Thoni, A. $100 \mathrm{MW}$ full-size converter in the Grimsel 2 pumped-storage plant. In Proceedings of the HYDRO 2013 Promoting the Versatile Role of Hydro, Innsbruck, Austria, 7-9 October 2013.

9. Henry, J.M.; Houdeline, J.B.; Ruiz, S.; Kunz, T. How reversible pump-turbines can support grid variability: The variable speed approach. In Proceedings of the HYDRO 2012 Innovative Approaches to Global Challenges, Bilbao, Spain, 29-31 October 2012.

10. Dong, R.; Chu, S.; Katz, J. Quantitative visualization of the flow within the volute of a centrifugal pump. Part B: Results and analysis. J. Fluids Eng. 1992, 114, 396-403. [CrossRef]

11. Akin, O.; Rockwell, D. Flow structure in a radial flow pumping system using high-image-density particle image velocimetry. J. Fluids Eng. 1994, 116, 538-544. [CrossRef]

12. Sinha, M.; Pinarbasi, A.; Katz, J. The flow structure during onset and developed states of rotating stall within a vaned diffuser of a centrifugal pump. J. Fluids Eng. 2001, 123, 490-499. [CrossRef]

13. Sano, T.; Nakamura, Y.; Yoshida, Y.; Tsujimoto, Y. Alternate blade stall and rotating stall in a vaned diffuser. JSME Int. J. Ser. B 2002, 45, 810-819. [CrossRef]

14. Gonzales, J.; Santolaria, C.; Blanco, E.; Fernandez, J. numerical simulation of the dynamics effects due to impeller-volute interaction in a centrifugal pump. J. Fluids Eng. 2002, 124, 348-355. [CrossRef]

15. Byskov, R.K.; Jacobsen, C.B.; Pedersen, N. Flow in a centrifugal pump impeller at design and off-design conditions-Part II: Large Eddy Simulations. J. Fluids Eng. 2003, 125, 73-83. [CrossRef]

16. Pedersen, N.; Larsen, P.S.; Jacobsen, C.B. Flow in a centrifugal pump impeller at design and off-design conditions-Part I: Particle image velocimetry (PIV) and laser doppler velocimetry (LDV) measurements. J. Fluids Eng. 2003, 125, 61-72. [CrossRef]

17. Sano, T.; Yoshida, Y.; Tsujimoto, Y.; Nakamura, Y.; Matsushima, T. Numerical study of rotating stall in a pump vaned diffuser. J. Fluids Eng. 2002, 124, 363-370. [CrossRef]

18. Cavazzini, G.; Pavesi, G.; Ardizzon, G. Pressure instabilities in a vaned centrifugal pump. Proc. Inst. Mech. Eng. Part A J. Power Energy 2011, 225, 930-939. [CrossRef]

19. Majidi, K. Numerical study of unsteady flow in a centrifugal pump. J. Turbomach. 2005, 127, 363-371. [CrossRef]

20. Guo, S.; Maruta, Y. Experimental investigations on pressure fluctuations and vibration of the impeller in a centrifugal pump with vaned diffusers. JSME Int. J. Ser. B 2005, 48, 136-143. [CrossRef]

21. Pavesi, G.; Cavazzini, G.; Ardizzon, G. Time-frequency characterization of the unsteady phenomena in a centrifugal pump. Int. J. Heat Fluid Flow 2008, 29, 1527-1540. [CrossRef]

22. Gentner, C.; Sallaberger, M.; Widmer, C.; Braun, O.; Staubli, T. Analysis of unstable operation of pump turbines and how to avoid it. In Proceedings of the HYDRO 2012 Innovative Approaches to Global Challenges, Bilbao, Spain, 29-31 October 2012.

23. Yang, J.; Pavesi, G.; Yuan, S.; Cavazzini, G.; Ardizzon, G. Experimental characterization of a pump-turbine in pump mode at hump instability region. J. Fluids Eng. 2015, 137, 1109-1119. [CrossRef]

24. Pavesi, G.; Cavazzini, G.; Ardizzon, G. Time-frequency characterization of rotating instabilities in a centrifugal pump with a vaned diffuser. Int. J. Rotating Mach. 2008, 2008. [CrossRef]

25. Pavesi, G.; Cavazzini, G.; Yang, J.; Ardizzon, G. Flow phenomena related to the unstable energy-discharge characteristic of a pump-turbine in pumpmode. In Proceedings of the 15th International Symposium on Transport Phenomena and Dynamics of Rotating Machinery, Honolulu, HI, USA, 24-28 February 2014.

26. Pavesi, G.; Yang, J.; Cavazzini, G.; Ardizzon, G. Experimental analysis of instability phenomena in a high-head reversible pump-turbine at large partial flow condition. In Proceedings of the 11th European Conference on Turbomachinery Fluid Dynamics and Thermodynamics, Madrid, Spain, 23-27 March 2015.

(C) 2016 by the authors; licensee MDPI, Basel, Switzerland. This article is an open access article distributed under the terms and conditions of the Creative Commons Attribution (CC-BY) license (http://creativecommons.org/licenses/by/4.0/). 